\title{
The Effectiveness of A Training Program Based on Developing the Level of Fine Motor Skills for Students with Autism Spectrum
}

\author{
Dr.Samar Fahmi Taher Amer
}

\begin{abstract}
The study aimed to identify the effectiveness of a training program on the level of fine motor skills for students with autism spectrum. Specifically, this study sought to examine the following hypothesis: There is no statistically significant difference at the level of significance $(\alpha=0.05)$ between the experimental and control groups on the fine motor skills scale attributed to the training program. The study population consisted of students classified with the autism spectrum in the comprehensive rehabilitation center for special education, which numbered (16) male and female students, and the sample was chosen in a stratified random manner, as the number of its members reached (8) male and female students, The program's precise motor skills test was used. The training program was applied to the experimental group. In order to analyze the results of the study, the associated contrast analysis (ANCOVA) was used. The results of the study found that there is a statistically significant difference at the level of significance (05.) 0 in the level of fine motor skills in favor of the experimental group compared to the control group. The study also found that there was no statistically significant difference in the level of fine motor skills due to the gender variable.
\end{abstract}

Keywords: training program, fine motor skills, autism spectrum.

DOI: $10.7176 / \mathrm{JEP} / 11-16-07$

Publication date:June 30th 2020

\section{Introduction to the study}

All educational institutions seek to develop programs offered to students with special needs to reach their capabilities to the best possible level, and the category of people with autism spectrum that represents not a few among those with special needs has captured a lot of interest, represented in the programs that are presented to them to develop their capabilities in the centers, and that the development Programs have become an essential and important component of educational programs and one of the most important aspects of children with autism spectrum that are the basis in the learning process.

The use of programs commensurate with the capabilities of the student with the autism spectrum and is consistent with the inclination and desires of the goals and content, and all studies agree that the student with the autism spectrum needs special programs imposed by the student's autism spectrum, and among these important aspects is that the student with the autism spectrum suffers from a deficiency In the use of motor skills in general and precise movements in particular, which is a prerequisite for learning.

The problem of the study and its questions: As many studies indicated, Al-Smadi (2018) mentioned that students with the autism spectrum have a low level of perception and response as a result of the irregularity of the neuronal signs that appear through random motor skills, whether they are fine or large movements and high it becomes necessary to provide A training program for developing fine motor skills.

All studies emphasized the importance of fine motor skills for students with autism spectrum in the learning process.

- Lack of studies that used special programs to develop the fine motor capabilities of students with autism spectrum.

The hypothesis of the study:

- There were no statistically significant differences at $(\alpha \geq 0,05)$ between the mean scores of the experimental group and the mean scores of the control group the accurate motor skills scale for students with autism spectrum attributed to the variable of the training program.

Objectives of the study :

Providing a training program to develop fine motor skills for students with autism spectrum.

- Identify the level of fine motor skills for students with autism spectrum.

the importance of studying :

The importance of this study is in two aspects:

The first: theoretical importance:

- Revealing the effectiveness of a training program on the level of fine motor skills for students with autism spectrum.

- The use of computerized educational programs for the phenomenon of deficiency in the level of fine motor skills for students with autism spectrum.

Second: Applied Importance:

Providing a training program to develop fine motor skills for students with autism spectrum. 
- The program is used by supervisors to develop and develop the fine motor skills of students with autism spectrum.

\section{Study limitations:}

- Using the fine motor skills test to identify the level of students with autism spectrum of the study sample. Registered in the Comprehensive Rehabilitation Center for Special Education, where the teachers implemented for a period of one month starting from $1 / 2 / 2020$.

\section{Chapter II}

\section{Theoretical framework and previous studies Introduction}

Autism spectrum disorder is a developmental disorder that affects children in early childhood. It affects behavioral, social and linguistic aspects and has developmental effects and has developmental effects on the child, his family and the individuals surrounding him. The characteristics of children with autism spectrum disorder differ from other children, as they tend to isolate and not play with others and do not wish to integrate into society. This point is considered a major problem For them and their families Also, it is natural to see ordinary children participating and playing with others while we find that children of the autism spectrum tend to isolate and play on their own and do not share their games and interests to others, given that their playing style differs from ordinary children and this is due to the presence of a central nervous disorder of the child with autism spectrum disorder (Al-Qamish, 2017).

The autism spectrum disorder is also considered the primary cause of social, verbal and non-verbal communication of children. This disorder prevents their imaginary activity and their mutual social interaction with others, as this disorder is observed during the first eight years of the child's life and its symptoms are completely clear in the first thirty months of life because it begins to Abnormal development and introverted behavior (Hilal, 2018).

Children with autism spectrum disorder suffer from disturbances in fine motor skills and these skills include the activity of small muscles, the consistency of their work, and muscles in the muscles of the fingers and hands and the use of muscles in the performance of the small movement, that is, the performance of which requires the use of these muscles such as writing, drawing, holding keys and daily actions such as scanning. And washing and cutting vegetables. As the importance of developing fine motor skills among autistic children, due to the child's need for these muscles in everything that enters the process of regular education, and all that prepares and vocational training, such as writing, drawing, manual work of all kinds, sign language, gesture, and the use of things of various different types, simple and complex (Rawashdeh), Olayan, 2016).

\section{Definition of autism spectrum disorder:}

The word autism refers to Greek civilization (Autos) and means the self that was used for the first time by the psychologist Eugene Boller in 1911 to describe withdrawal and social attachment among people suffering from schizophrenia, and the word as we use it was used by Kanner in 1943 and the Kanner study was considered a basis for the definition of autism (Pavilion, 2018).

The American Handicapped Personality Act defines autism spectrum disorder as: a developmental disorder characterized by insufficient interaction and social communication, stereotypical movements, resistance to change in daily routines, and an abnormal response to sensory stimuli, and these characteristics are observed before the age of eight (Zureikat, 2016).

Autism is also categorized as a comprehensive developmental strike, which shows its most important symptoms in the first year of the child's life, as it is a disorder characterized by deficiencies in the social and communicative aspect with others, as it is characterized by a very limited interest in activities, play and imagination, in addition to repetitive and stereotypical behaviors that have importance Significant in early diagnosis of autism spectrum disorders (Deeb, 2016) and (Arzu, 2015).

Psychologist leo kanner (1943) showed the meaning of autism by observing eleven mentally retarded children at Harvard University in the United States of America and he described a set of behaviors and distinctive characteristics of autism disorder which is the child's inability to develop his social relationships with others, and his delay In its acquisition of speech, non-communicative use of speech after its development, and stereotypical and iterative play activities. There has been a set of attempts to distinguish between the most important behavioral manifestations that appear on this disorder with other disorders and this is what was focused on modern research (2015 Borsboom and Geurts, Ruzzano).

Mudallal (2015) pointed out that autistic disorder makes the child suffer from isolation and introvertedness, does not realize what is going on around him, does not want team play, and does not feel the dangers that are around him, which results in fear, and this disorder makes him rejoice and saddened laughing and crying for no reason, Many of the disorders that fall under the name of autism or autism spectrum.

Prevalence of autism spectrum disorders: One of the official estimates, which are accurate, is the studies issued by the American Center for Prevention and Control of Diseases, which recorded the incidence of autism in one of every 110 children (Al-Reikat, 2017). 


\section{Causes of autism spectrum disorder:}

Many researchers have come to the causes of this disorder. Some have interpreted this disorder as a result of social and psychological reasons, while others see that there are biological factors, genetic factors, chemical factors, or organic causes, and there is still ambiguity about the cause of autism spectrum disorder. These reasons are:

Genetic factors: where autism spectrum disorder is associated with chromosomal abnormalities due to the presence of a relationship with the chromosome $(\mathrm{x})$ and that it interferes with $(5-16 \%)$ of all cases. When looking at the family and twins more than the subject of heredity, it has been observed that about (2\%) of families have them Two children with autism.

Biological factors: The occurrence of brain damage before, after or after birth, or even during disturbances through the mother's infection with rubella, encephalitis or suffocation during childbirth, and complications of childbirth appear significantly in children with autism spectrum disorder compared to other healthy people or Even those with other disorders.

Cognitive impairment: The autism spectrum disorder is due to cognitive impairment and the child's inability to organize sensory receptors, which prevents his ability to store interconnected thoughts and has a meaning about the surrounding environment and also works to limit his ability to adapt and learn with the environment and thus works to isolate the child and close to himself He has a defective auditory perception that his parents think their child is deaf.

Psychological and family factors: It is one of the most important explanations for the occurrence of this disorder as it depends on the methods of education and psychological factors and emphasizes the role of parents in causing this disorder, especially the mother and its relationship to the child and the lack of emotional attachment to the child.

Environmental pollution: The environmental pollution that the child is exposed to during the critical developmental stage, such as toxic chemicals, lead and mercury, that affect the child's development in different areas of development.

Nervous system dysfunction: It was found that (4-32\%) of children with autism spectrum disorder suffer from epileptic seizures at some time during their lives, and it has been observed that children with autism spectrum disorder have high nerve attacks that appear more during puberty, some of which are evident from During dyskinesia and that $(25 \%)$ or more have a history of seizures.

Conditions of pregnancy and childbirth: These are dyslexia, problems associated with childbirth and delay, and other reasons accompanying the birth process, such as the use of some medical tools that pull the fetus and that may affect the brain. (Mukhaddamah, 2019).

Manifestations of autism spectrum disorder:

Autism spectrum disorder is characterized by several set of characteristics, including poor communication and delay in the expressive language represented in the expressive language and weak awareness of instructions repeated in words without meaning, as there are several characteristics that characterize children with autism disorder: linguistic insufficiency, some people only make voices and some listen for a few Of the words, others listen only for the words (Al-Khatib, 2018).

Behavioral characteristics: Among the most important problems that specialists and parents face in providing appropriate educational services, the most important of which are mentioned are typical movements such as flapping hands, shaking the body and waving the hand in front of the eyes, circling around the soul, and walking on the heads of the toes. (Abu Zaitoun, 2017).

Social characteristics: Children with autism spectrum disorder are characterized by the inability to participate in social relationships, and disturbances in the ability to make friends.Children's studies with autism spectrum disorder are divided into three sections based on their social interaction:

First: The distant (Aloof) They are the ones who do not show any kind of interest or attachment or demand for help and get angry when others approach them and reject any kind of physical appeal.

Second: Passive. They do not initiate social interaction, but they are safe from the initiatives of other people to interact with them.

Third: Active Butodd interacts in a social way, but in an inappropriate and reprehensible manner, which results in their disapproval and rejection (Al-Barry, 2017).

Effective intervention programs and methods in dealing with students with autism spectrum disorder:

Al-Hiyari (2017) states that there are several treatment programs used with students with autism spectrum disorder, which aim to raise student levels in many areas, the most important of which are:

Denver early intervention model (ESDM)

The Denver model has confirmed its success in developing many aspects, including mobility, social and cognitive, among students with autism spectrum disorder, including various strategies that work in the home and school and is based on many games and activities and imitation and the exchange of feelings and the promotion of symbolic thinking and communication activities and trying to achieve many of the Objectives including: 
1- Improving language skills and social communication skills

2- Encouraging the formation of relationships with non-disabled colleagues, and also encouraging social interactions

3 Preventing disruptive behaviors by combining job evaluation and self-management strategies

4- Early intervention and assistance in detection

5 Improve student performance on academic and school assignments and activities

6 Extending student interests and limiting stereotypical behaviors (Abu Khalil, 2017).

\section{Axial Response Therapy (PRT)}

The model focuses on investing natural education opportunities that bring together students with autism spectrum disorder and regular students in the natural environment by training colleagues to enhance the social competence of autistic students using various pivotal response training strategies, and mentioned among them strengthening and diversification in games and providing diverse opportunities and gain attention and encourage talks and prolonged Storyboarding and role-playing games (Zureikat, 2016).

Teach program for the treatment and education of students with autism spectrum disorder and children with communicative disabilities (TEACCA):

It is a program for treating and raising autistic children and the accompanying communication disorders, as designed by Nichols, it is a program supportive of the educational necessity from early childhood until adulthood, and teachers are required to train them in cooperation with parents and children's therapists, as the program focuses on the autistic child to make programs for the needs of the child with autism spectrum disorder It is also based on educating children with autism through their strength, which is their visual perception, and compensating them for their weaknesses, such as creating an environment for asylum as visual samples such as pictures and written words (Aweys, 2019).

\section{LOVAAS Program:}

Lovas program is one of the early intervention programs for children with autism spectrum disorder, which was based on the theory of applied behavioral analysis (ABA). Lovas method is based on the use of conditional response and training significantly and the training period is not less than forty hours per week, and the family participates in the program, and its method depends on Shaping behavior by reinforcement gradually or by successive approximation using encouragement and induction procedures. The desired promoter of a child with autism spectrum disorder should be tested as favorite foods and the game he desires (Al Bakr, 2016).

It is reported that Lovas' program has achieved positive results, therefore he worked on preparing a program (curriculum) and focuses on the idea of training on specific skills by relying on repetition to reach the stage of mastery, and is based on the fragmentation of skills to be taught to partial skills through which the student moves from one task to another gradually and has known this B Training through Discrete Attempts (DTT) (Amira, 2018).

Higashi programs (treating daily life skills)

This program initially started in 1964 in Tokyo for children with autism spectrum disorder or for those with developmental disorders. It is based on the assumption that these children can achieve their maximum potential, by providing them with the best assistance while they are beside their families. How to treat daily life skills depends on easy methods of what a child is expected to do. It has three main axes of Higashi learning technology that distinguishes the classroom that uses his technique from other classrooms:

1- Physical activities in groups through music, dance and art in order to enhance consistency and strength. Like running three times a day and daily outdoor sports activities such as football and basketball for one hour a day. An autistic spectrum disorder may benefit from this method, especially in reducing self-stimulation and improving attention.

2- Exposure to models to create mental stimulation.

3- Relying on group and organized activities in order to emphasize learning transferred from one child to another through imitation and help in developing emotional stability and dealing with the group (Zureikat, 2016).

\section{STAR Program:}

It is a comprehensive and behavioral program for children with autism spectrum disorder and developmental disabilities for the age group of children under 5 years, using school curricula in different data for children, and children learn basic skills through the use of applied behavior analysis strategies (ABA) and pivotal response training. Generalization during school routine tasks.

The program was designed to reduce to teachers a comprehensive set of plans and main tools for employing the program as part of the family support and individual educational plan. The program also provides important means for identifying the necessary skills for each child and for interactive monitoring and development of this skill as well as it provides behavioral strategies in training separate attempts that they found to be It was effective and appropriate in educating children with autism spectrum disorder and the program relies on teaching functional skills that are appropriate to each child's abilities apart from the other $(2015$, Arick \& loos \& falco \& krug). 


\section{PEERS}

A program that trains educational skills and skills that have a + relationship with learning, she was designed by Dr. Elizabeth Lagison in California in 2005 working on a 14-week intervention to develop the social skills of seventh-grade adolescents - for those who want to learn ways to help them create and maintain friendships. During the training period, important social skills are taught to adolescents, and they are given the opportunity to practice these skills during actual play activities during the training stages. Adolescents are taught how to make and maintain friendships, so parents can have feedback from their children through homework and socialization. The program depends on the development of several skills, the most important of which are:

1- How to use everyday conversation skills.

2- How to search for mutual interests between friends and exchange information.

3- Pranks and the way to enter and leave conversations between friends.

4- How to deal with rumors

5- How to deal with lies and arguments

6- How to choose the right friend

7- How to deal with aggression and reject it

Therefore, increasing the social skills of adolescents works to improve various skills, such as cooperation, responsibility, and improving social response (Abu Qara ', 2015).

Similar studies:

A study (Siyam and Omar, 2018) in Saudi Arabia entitled The effectiveness of using recreational small games in developing motor skills among autistic children and their impact on their functional skills related to daily activities. And a study (Abdul Samad, 2017) in Jordan entitled the effectiveness of a program based on teaching descriptive gestures in developing social expressive behaviors and motor skills among a sample of children with autism spectrum disorder. And a study (Hashem, 2016) entitled Fine motor skills among kindergarten children The study aims to identify the level of fine motor skills among kindergarten children, And in a study conducted by (Al-Qahtani, 2015) in Riyadh entitled the effectiveness of an educational program based on visual strategies in developing some motor skills among children with autism spectrum disorder. A study (2018, Azar \& Akbar) entitled The effect of motor cognitive training on the growth engine of children aged 8-10 years who suffer from high-functional autism spectrum disorder. And a study (Siyam and Omar, 2018) and Soo et al. (2016, So at al), entitled Using Animation to Promote Motor Skills in Children with Autism Spectrum Disorder. This study aimed to teach these children gestures by using video to develop motor skills provided by the robot, The study of Sue and others (2015, So at al) also aimed to compare children with autism spectrum disorder and children with developmental delay in the use and development of sign language and gestures and their ability to use hand movements after they were taught. A study (2014, Bremar) entitled Investigation of the effectiveness of the intervention of basic motor skills for 4-year-olds for those with autism spectrum disorder. In a study conducted by Kurt (2011, Kurt) in Turkey, it aimed to know the effectiveness of using sign language and movements while teaching autistic spectrum students to learn language reception skills.

Study methodology: The quasi-experimental approach was used to suit this study and the program was applied to two control and experimental groups.

Study community:

The study population consisted of children with autism spectrum in the 16-year special education center for special education.

The study sample:

The sample of the study consisted of (8) male and female students who were intentionally chosen from students with autism spectrum. A fine motor skills scale was applied before starting the procedures of applying the educational program, including (5) students and (3) students.

Study tool:

By reading the theoretical literature and studies in the field of motor skills and the stages of motor development, a fine motor skill test was used, and it includes the motor skills that are included in the training program.

Sincerity of the content:

To verify the validity of the test, it was presented in its primary form to ten specialists in special education, psychology, measurement and evaluation in universities, to determine the suitability of the test items for the current study and its society, as well as to judge the clarity of the test items for the field to which they belong, The percentage of agreement between the two arbitrators reached $90 \%$, and this percentage was considered appropriate and acceptable to judge the availability of truthful content for the scale.

Stability of the test:

To verify the significance of persistence, the fine motor skills scale was applied to a sample consisting of (8) male and female students with an autism spectrum from outside the study sample, and (8) male and female students from ordinary students and from the study community itself, and the stability of internal consistency was estimated using the Cronbach equation $\alpha$, on the scale as a whole, and in each field of the scale, the value of 
the Cronbach coefficient of $\alpha$ for the scale as a whole $(0.89)$, these scores confirm an acceptable level of test stability for this study.

The application of the test:

A group of (4) male and female teachers were trained, as all the requirements for launching the test and the estimated time for the application (15-20) minutes were prepared.

Theoretical basis for the training program:

-Since fine motor skills are essential for learning and gaining experience, they must be given adequate attention to the following considerations:

-Continuous training in fine motor skills makes an effective and tangible contribution to improving the level of performance.

-Fine motor skills are one of the primary developmental difficulties that are a reason for academic inability to learn (Al-Zayat, 1998a)

-Students with autism spectrum performance may improve if they use strategies to improve and develop fine motor skills (Smadi and Shamali 2017).

- The development of fine motor skills helps students with the autism spectrum to possess permanent skills that help them in developing their different abilities.

Methods included in the program:

Due to the difference in the capabilities of students with autism spectrum and the clear contrast between them, the program was implemented individually through direct supervision by the teacher, as the program included a set of activities and games aimed at so that we can activate the fine motor skills and work with high efficiency The program includes: -

- Give instructions - Feedback - Make and repeat some forms - Implement the program - Promote the student Repeat the skill.

\section{Certify the content for the boot camp:}

The program was presented to a group of arbitrators, with the aim of identifying the appropriateness of the objectives, their relevance to the content of the program, the appropriateness of the educational procedures used, the appropriateness of language formulation, and the group of students with the autism spectrum. The program has been modified in the light of the arbitrators 'comments, and the agreement between the two arbitrators has reached $92 \%$. This is an important indicator of the validity of the content and is acceptable for research purposes. Procedures for implementing the training program:

After obtaining approval to implement the program, a training workshop was conducted for the two teachers and the female teacher supervising the application of the tests and applying the educational program, by providing them with a sample program where the students were distributed to two control and experimental groups.

The program consisted of ten classes of three sessions per week for three weeks. The program was applied to the experimental group and was not applied to the control group.

Study design and statistical treatment:

The semi-experimental design was used: the equivalence groups with pre-test and post-test.

Experimental group $\mathrm{O} 1 \mathrm{X} \mathrm{O} 2$

Control group $\mathrm{O} 2$ - $\mathrm{O} 2$

Results :

To verify the study hypothesis, "there are no statistically significant differences at the level $(\alpha=0.05)$ between the members of the experimental group and the control group on the scale of fine motor skills."

The adjusted averages for the performance of the experimental and control groups were extracted on the fine motor skills scale. Table (1) shows the adjusted averages of the results of the post test for the scale of fine motor skills according to the group variable.

Table (1) Modified averages of the post test results for fine motor skills

Depending on the group variable

\begin{tabular}{|l|l|l|}
\hline group & Tribal mean & dimensional mean \\
\hline Experimental group & 50,24 & 60,87 \\
\hline Control group & 51,22 & $52<62$ \\
\hline
\end{tabular}

It is clear from Table No. (1) that the average mean for performing the post-test performance of the fine motor skills of the experimental group is (60.87), while the average performance of the control group for the post-test (52.65). If these differences are statistically significant at the level $(\alpha=05.0)$, then the co-variance analysis was used for the post test as shown in Table (2). 
Table (2) Summary of( ANCOVA) to examine differences on the dimensional scale By group for fine motor skills

\begin{tabular}{|l|l|l|l|l|l|}
\hline Source of contrast & $\begin{array}{l}\text { Sum of } \\
\text { squares }\end{array}$ & $\begin{array}{l}\text { Degree } \\
\text { freedom }\end{array}$ & $\begin{array}{l}\text { Average sum of } \\
\text { squares }\end{array}$ & value of p & $\begin{array}{l}\text { Significance } \\
\text { leve }\end{array}$ \\
\hline $\begin{array}{l}\text { Tribal sign of fine } \\
\text { motor skills }\end{array}$ & 656,19 & 1 & 656,19 & 56,03 & 0,00 \\
\hline group & 3465,05 & 1 & 3465,05 & 298,85 & 0,00 \\
\hline roing & 503,56 & 45 & 11,71 & & \\
\hline total & 12470,00 & 47 & & & \\
\hline
\end{tabular}

The results of the co-variance analysis indicated in Table 3 indicated that there were statistically significant differences $(\alpha=05.0)$ on the variable motor skills with degrees of freedom (48-1), and the level of significance (000. 0) and the value of $P$ was as it came In the table (295.88) and the significance level (00.0). To find out the impact of the training program, the test was re-applied to the experimental and control groups a month after the end of the program, as shown in Table No. (3).

Tabl (3)Modified averages for the experimental group and control on the pre and post retention scale For fine motor skills

\begin{tabular}{|l|l|l|l|}
\hline group & Tribal average & Dimensional mean & Average retention \\
\hline Experimental group & 50,24 & 60,78 & 60,33 \\
\hline Control group & 51,22 & 62,65 & 62,68 \\
\hline
\end{tabular}

Table No. (3) shows that there is an apparent difference in the adjusted averages of the retention test between both the experimental group and the control group for fine motor skills, where the adjusted average degree of retention of the experimental group (60.33) while the adjusted average of the retention measure of the control group (52.68), and to find out If this difference is statistically significant at the level of $(\alpha=05.0)$, a common variance analysis was used to detect these differences,

Tabl(4) Abstract ANCOVA to examine differences on group retention scale for fine motor skills

\begin{tabular}{|l|l|l|l|l|l|l|}
\hline Source of contrast & $\begin{array}{l}\text { Sum of } \\
\text { squares }\end{array}$ & $\begin{array}{l}\text { Degree of } \\
\text { freedom }\end{array}$ & $\begin{array}{l}\text { Average sum of } \\
\text { squares }\end{array}$ & $\begin{array}{l}\text { value of } \\
\mathrm{p}\end{array}$ & $\begin{array}{l}\text { Significance } \\
\text { leve }\end{array}$ \\
\hline $\begin{array}{l}\text { Tribal sign of fine } \\
\text { motor skills }\end{array}$ & 418,56 & 1 & 418,56 & 52,95 & 0,00 \\
\hline group & 3748,67 & 1 & 3748,67 & 474,24 & 0,00 \\
\hline roing & 339,89 & 45 & 7,90 & & \\
\hline total & 12470,00 & 47 & & & \\
\hline
\end{tabular}

The results of the co-variance analysis, as shown in Table 4, indicate that there are statistically significant differences $(\alpha=05.0)$ on the fine motor skills variable on the retention scale where the value of P (474.24) reached degrees of freedom (1-48) and the level of significance (00) 0$)$ This value is statistically significant. This result is consistent with the study (2014, Bremar) study (2018, Azar \& Akbar), and this significant difference between the two groups in favor of the experimental group is due to the positive impact of the program on the growth and development of fine motor skills.

\section{refrains}

-Owais, Sarah Adel Jabri (2019), Challenges Parents of children with autism spectrum disorder participate in treatment and educational programs for their children in Oman and find solutions to address them, unpublished master thesis. University of Jordan .

- His suppression, Muhammad Qasim (2019), behavioral characteristics of children with autism spectrum disorder and its treatment with stress and anxiety 'unpublished master's thesis, University of Jordan, Jordan.

-Hilal, Asmaa (2018), Rehabilitation of Al-Maween, Amman, Dar Al-Maisarah for Publishing and Distribution.

- Sharjah, Ahmed Talal Ahmed (2018), the effectiveness of a training program based on behavioral theory to improve social skills among a Saudi sample of people with autism spectrum disorder, unpublished doctoral dissertation, International Islamic Science University, Jordan.

-Siyam and Omar, Khaled Saeed and Mohamed Kamal (2018), the effectiveness of using recreational small games in developing motor skills among autistic children and their impact on job skills related to daily life activities, Educational Journal, No. 51.

- Amira, Mervat Yusef (2018), the effectiveness of the educational support model for mothers in developing communication and social interaction skills and reducing forms of stereotypical behavior for children with autism spectrum disorder enrolled in special education centers, unpublished doctoral thesis, University of Jordan, Jordan.

- Al-Hayyari, Haitham Abdul-Rahman (2018), the effectiveness of a training program based on the techniques of behavior modification in the account mothers of children with autism spectrum disorder in the United Arab 
Emirates and the skills to deal with the behavior of their children, unpublished PhD, University of Jordan.

- Al-Khatib, Razan Noman, (2018), designing a curriculum based on teaching numerical skills and investigating effectiveness in the acquisition of mathematical skills and their use among a sample of children with autism spectrum disorder in Jordan, unpublished PhD thesis, University of Jordan.

-Al-Barry, Ikhlas Nawaf (2017), The Effectiveness of a Training Program Based on Behavior Modification for Teachers of Students with Autism Spectrum Disorder in Reducing Behavioral Problems and Development of Social Behavior of Their Students, Unpublished Doctorate Thesis, University of Jordan.

Abdel-Samad, Hanin Ibrahim (2017), Effectiveness of a program based on teaching functional gestures in the development of expressive social behaviors and motor skills among a sample of children with autism spectrum disorder, unpublished PhD thesis, University of Jordan.

Al-Qamash, Mustafa, (2017), Multiple Disabilities, Amman, Dar Al-Maysarah for Publishing and Distribution.

- Abu Khalil, Sanaa Zahir Hosni (2017), the effectiveness of a training program for fellow students with autism spectrum disorder integrated in the regular school in improving social interaction skills and reducing behavioral problems among these students, unpublished Master Thesis, University of Jordan.

-Abu Zaitoun, Sulaiman Musa (2017), Effectiveness of reinforcement in developing self-control skills and social interaction among children with autism spectrum disorder, unpublished master's thesis, University of Jordan, Jordan.

-Rollards, Hussein Abdullah (2017), a behavioral training program for the siblings of children with autism spectrum disorder to improve the social and communication skills of these children, unpublished Master Thesis, University of Jordan, College of Graduate Studies, Jordan.

-Al-Zureikat, Ibrahim Abdullah (2016), Autism Behavior, Diagnosis and Therapy, Amman, Wael House for Publishing and Distribution.

- Hashem, Sajla Faeq (2016), Fine Motor Skills for Kindergarten Children, Journal of the College of Education for Girls, Volume 27

Al-Deeb, Abeer Arafa Abdel Aziz (2016), Psychological Stress and the Needs of Mothers of Children with Autism Spectrum Disorder and Their Relationship in the United Arab Emirates, Unpublished Master Thesis, United Arab Emirates University

- Al-Rashda , Alyan, Mamdouh Moussahani Shehadat (2016), the effectiveness of a behavioral training program to develop some fine motor skills among autistic children, Journal of the Faculty of Educational Sciences, second edition, part 2.

- Al-Zureikat, Ibrahim Abdullah (2016), Early Intervention Forms and Procedures, Amman, Dar Al Masirah for Publishing and Distribution

-Al-Bakkar, Hamza Abdel-Hafiz (2016) Effectiveness of a play-based training program in developing cognitive skills for children with autism spectrum, unpublished doctoral dissertation, University of Jordan, College of Graduate Studies, Jordan.

-Mudallal, Shahrazad (2015), Psychosocial characteristics of an autistic child from the point of view of nannies, Unpublished Master Thesis, University of Mohamed Khidr, Algeria.

-Abu Qaraa, Mai Issa, (2015), MA thesis entitled Quality of Life for Families of Children with Autism Spectrum Disorder and its Relationship to Some Variables in Jordan, University of Jordan, College of Graduate Studies, Jordan, Amman.

-Al-Qahtani, Abdullah Saleh (2015), a study entitled the effectiveness of an educational program based on visual strategies to develop some motor skills among children with autism spectrum disorder, the International Educational Journal of Specialization.

-So, M,. Wong, J.. Cabibihan, C, Lam, R, Chan, H, Qians, Children With autism spectrum desorders, Journal of Computet Assisted Learning,

-Ruzzano, L, Borsboom, D, \& Geurts, H .(2015). Repetitive behaviors in autism and obsessive- compulsive disorder: New perspective from a network analysis. Journal of Autism Development Disorders,

-Arick J. R\& Loos L\& Falco R\& Krug D. A ( 2015) STAR Program. by PRO-ED Inc. Austin, Texas.

-So , Wing Chee. Lui'aming .Wong, b Tze kiu . and sita ,Long Tin, (2015). The Use of Hand Gestures to Communication About Nonpresent objects in Mind Among Children with Autism spectrum Disorder, Journal of speech, Language Hearing Association.

-Arzu, O. (2015). Effectiveness of Siblings-Delivered iPad Game Activities in Teaching Social Interaction Skills to Children with Autism Spectrum Disorders, Anadolu University, 1 . preschool children conii Gothenburg,

-Kurt, O. (2011). A comparison of discrete trial teaching with and without gestures $\backslash$ signs in teaching receptive language skills to children with autism. Educational sciences: theory and practice .

-Bremer, Emily (2014) Study titled : Investigating the Effectiveness of a Fundamental Motor Skill Intervention for 4 Year Old Children with Autism Spectrum Disorder, Investigating the Effectiveness of a Fundamental Motor Skill Intervention for 4 Year Old Children with Autism Spectrum Disorder , Master of Health Sciences In The Faculty of Health Sciences Kinesiology University of Ontario Institute of Technology . 